\title{
Palo Verde. Un centro secundario en la zona de Cotzumalguapa, Guatemala
}

Oswaldo Chinchilla Mazariegos, Sébastien Perrot-Minnot y José Vicente Genovez

\section{(2) OpenEdition}

12 Journals

Edición electrónica

URL: http://journals.openedition.org/jsa/1876

DOI: $10.4000 /$ jsa. 1876

ISSN: 1957-7842

\section{Editor}

Société des américanistes

\section{Edición impresa}

Fecha de publicación: 1 enero 2001

Paginación: 303-324

ISSN: 0037-9174

\section{Referencia electrónica}




\title{
PALO VERDE \\ UN CENTRO SECUNDARIO \\ EN LA ZONA DE COTZUMALGUAPA, GUATEMALA
}

\author{
Oswaldo Chinchilla Mazariegos*, Sébastien Perrot-Minnot**, \\ José Vicente GeNOVEZ***
}

La zona de Santa Lucía Cotzumalguapa, en la costa pacífica de Guatemala, es célebre desde el siglo XIX por sus esculturas, que datan del período clásico tardío y quizás se continuaron elaborando hasta inicios del Postclásico (600-1000 d.C.). La mayor concentración de esculturas se encuentra en la «Zona Nuclear de Cotzumalguapa ", un centro urbano que en su apogeo cubría más de diez kilómetros cuadrados. Las investigaciones recientes han demostrado que los sitios tradicionalmente conocidos como Bilbao, El Baúl y El Castillo no son sino los principales conjuntos de arquitectura y escultura monumental dentro de esta extensa ciudad. Cotzumalguapa fue uno de los principales centros de poder político e innovación cultural de su época en el sur de Mesoamérica. El estilo escultórico Cotzumalguapa se encuentra en numerosos sitios de la costa y altiplano central de Guatemala, desde el departamento de Suchitepéquez hasta la frontera con El Salvador, en una franja que se extiende $180 \mathrm{~km}$ de este a oeste (Figura 1). Uno de los principales conjuntos escultóricos fuera de la Zona Nuclear se encuentra en el cercano sitio de Palo Verde, que fue objeto de investigaciones en diciembre de 2000 y enero de 2001. Los objetivos de este trabajo fueron: a) documentar la arquitectura visible en el sitio por medio de mapeo; b) determinar la extensión de los asentamientos asociados al sitio por medio de reconocimientos ; c) documentar en forma básica la historia ocupacional del sitio por medio de excavaciones estratigráficas. En conjunto, estos objetivos se orientaron a producir documentación básica sobre uno de los sitios más importantes en el sistema de asentamientos asociado a la Zona Nuclear de Cotzumalguapa. Este artículo resume los resultados de estas investigaciones $\mathrm{y}$, a la vez, ofrece un reporte de dos esculturas anteriormente desconocidas, que de acuerdo a informes orales, provienen del sitio de Palo Verde.

* Museo Popol Vuh, Universidad Francisco Marroquín, 6a calle final zona 10, Guatemala 01010. Correo electrónico : ofchinch@ufm.edu.gt

** Université de Paris I (Panthéon-Sorbonne), Équipe d'Accueil et de Recherche en Archéologie Précolombienne, 3, rue Michelet, 75006 Paris. Correo electrónico : sebpm@hotmail.com

*** Proyecto Arqueológico Cotzumalguapa, Museo Popol Vuh, Universidad Francisco Marroquín, 6a calle final zona 10, Guatemala 01010. Correo electrónico : jvgenovez@latinmail.com

Journal de la Société des Américanistes 2001, 87, p. 303 à 324. Copyright $\odot$ Société des Américanistes. 


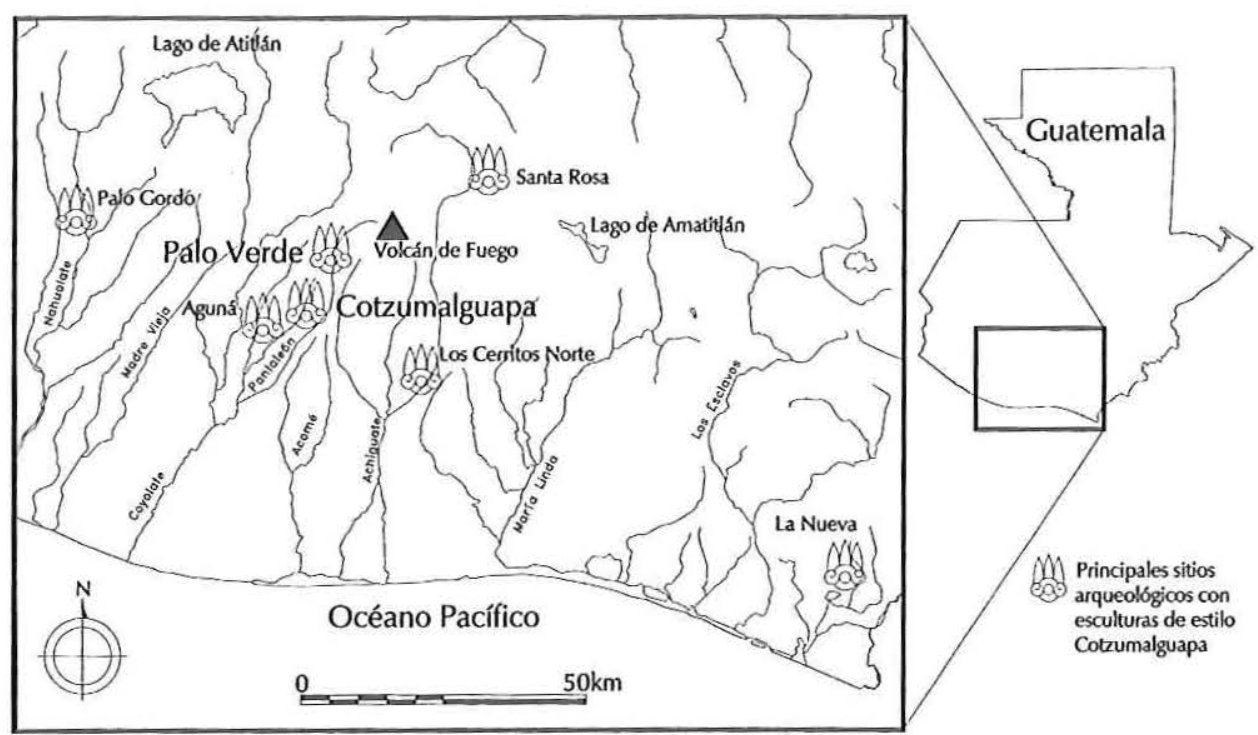

Fig. 1. - Localización de Palo Verde y otros sitios mencionados en el texto

\section{EL CONTEXTO GEOGRÁFICO}

Palo Verde está $12 \mathrm{~km}$ al norte de Santa Lucía Cotzumalguapa, a $890 \mathrm{~m}$ sobre el nivel del mar (Figura 1). El sitio se encuentra en la parte alta de la bocacosta, nombre que se le dá en Guatemala a la franja del pie de la cadena volcánica del Pacífico, aproximadamente entre 200 y $1000 \mathrm{~m}$ sobre el nivel del mar. La parte central del sitio se ubica en terrenos de la finca Giralda, y se detectaron extensos asentamientos en la finca Versalles, que se encuentra inmediatamente al este.

La localización geográfica de Palo Verde es uno de sus rasgos más intrigantes. El sitio se encuentra en las estribaciones de la falda sur del volcán de Fuego, a solamente $12 \mathrm{~km}$ del cráter, el cual se eleva $3763 \mathrm{~m}$ sobre el nivel del mar. El volcán de Fuego se ha mantenido activo desde el siglo XVI, y seguramente muchos siglos atrás (Williams 1960). Desde fines del siglo XIX se han documentado fuertes episodios eruptivos en 1880, 1932, 1957 y 1974. Como consecuencia, la superficie del sitio arqueológico se encuentra cubierta por una capa de cenizas que alcanza más de $60 \mathrm{~cm}$ en algunos lugares. Las constantes erupciones del volcán de Fuego debieron ser un factor importante en la vida diaria de los habitantes del sitio, que afectó sus actividades agrícolas, vías de comunicación, y su arquitectura monumental y doméstica.

Igualmente significativa es la cercanía del río Pantaleón, que corre $500 \mathrm{~m}$ al este del sitio. Este río desciende torrencialmente desde la vertiente oeste del macizo de los volcanes de Fuego y Acatenango, arrastrando consigo una enorme cantidad de sedimentos. Su flujo normal, de $4.25 \mathrm{~m}^{3} /$ segundo, se elevó a $589.46 \mathrm{~m}^{3} /$ segundo durante una descarga torrencial en 1971 (Gonzáles Quezada 1974, pp. 145-149). Tras la erupción del volcán de Fuego en 1974, el río acarreó 1726000 toneladas de 
sedimentos anualmente (Davies et al. 1978). Esto puede constituir un riesgo aun en épocas de actividad volcánica normal ; durante la temporada de lluvias del año 2000, el río arrastró una enorme masa de sedimentos que obstruyó completamente una toma de agua situada a poca distancia de Palo Verde, la cual abastece a los ingenios Los Tarros y El Baúl. Cabe especular sobre los efectos de estos torrentes y los sedimentos que arrastran sobre las poblaciones prehispánicas de la zona.

La parte central del sitio ocupa una franja de terreno con leve pendiente de norte a sur, que desciende también gradualmente al este hacia la garganta del río Pantaleón, y al oeste hacia una profunda y sinuosa quebrada, conocida localmente como « quebrada grande ». Además de distanciarlo convenientemente del torrencial río Pantaleón, esta localización confiere al sitio un carácter potencialmente defensivo. Al oeste de la quebrada grande se elevan dos cerros que alcanzan $940 \mathrm{~m}$ sobre al nivel del mar. Estos cerros son los más prominentes de la zona, fácilmente visibles desde El Baúl y El Castillo, por lo que pudieron haber jugado un papel en las comunicaciones entre Palo Verde y la Zona Nuclear.

En la actualidad, la parte central del sitio, en terrenos de la finca Giralda, se encuentra sembrada de café, que ha sido el cultivo predominante desde el siglo XIX. Hacia el norte hay amplios sectores dedicados a pastos para ganado en terrenos de la finca Palo Verde. En años recientes se introdujo el cultivo de la caña de azúcar, que cubre la pendiente al este del sitio, bajando hacia el río Pantaleón, en terrenos de la finca Versalles. La garganta del río conserva todavía algo de la vegetación original de la zona, un bosque tropical denso que abriga una gran variedad de fauna. La zona es irrigada por numerosos riachuelos que afluyen hacia el Pantaléon.

Por su localización, cabe preguntarse si el sitio pudo jugar un papel en el control de las vías de comunicación entre la Zona Nuclear de Cotzumalguapa y el altiplano de Chimaltenango. Actualmente, existen varias rutas que comunican fincas y aldeas de la zona con las tierras altas, y una de ellas pasa junto al sitio. Todas estas rutas convergen en el pueblo de San Pedro Yepocapa, nueve kilómetros al norte de Palo Verde. La necesidad de rodear la falda del volcán de Fuego las convierte en vías empinadas y cubiertas de cenizas sueltas. La ruta más transitada actualmente corre unos tres kilómetros al oeste de Palo Verde, evitando de ese modo el paso del río Pantaleón, el obstáculo más importante que se presenta en las cercanías del sitio. Considerando los niveles de flujo que alcanza el río durante la estación lluviosa, este obstáculo debió ser importante aun en tiempos prehispánicos, cuando el tránsito se hacía a pie por grupos de cargadores. Sin embargo, no es imposible que Palo Verde haya sido un punto importante en el tránsito desde la Zona Nuclear de Cotzumalguapa en dirección a la zona de Yepocapa, y de allí hacia Chimaltenango. De hecho, ésta fue la ruta que utilizó Adolf Bastian en 1876, cuando bajó de Yepocapa a Santa Lucía Cotzumalguapa (Bastian 1878, pp. 437-38). Al presente, no es posible arribar a conclusiones más seguras sobre este problema, que sin duda es crucial para comprender las funciones económicas y políticas del sitio en relación con la Zona Nuclear.

\section{INVESTIGACIONES ANTERIORES}

A los ojos del investigador moderno, la escasa atención que ha recibido Palo Verde es chocante, considerando que el sitio se conoce desde el siglo XIX, y que tres de sus 
principales esculturas han estado expuestas en la ciudad de Guatemala desde inicios del siglo xx. Adolf Bastian (1878, p. 438) reportó primera vez un monumento del sitio, posiblemente el número 6, que se encontraba a la orilla del camino a Yepocapa. Sin embargo, fue Caecilie Seler quien escribió el primero y por casi un siglo el único reporte sobre el sitio, derivado de su visita en 1896 (Seler 1900, pp. 236-241). En esta oportunidad, la señora Seler fotografió los monumentos 1 al 6 , e hizo calcos de los principales relieves, uno de los cuales se conserva aún en la biblioteca del IberoAmerikanisches Institut, Berlin. Cabe citar la parte esencial de su informe, que, desafortunadamente, no incluyó una descripción o un plano del sitio :

\begin{abstract}
"Donde dejamos el camino había una piedra grande y tallada que representaba la cabeza de un jaguar, en muy mal estado por su antigüedad y varias influencias dañosas. Varios cientos de pasos hacia adentro del bosque se nos ofreció una vista que nos daba brincos el corazón de la alegría. Ahi estaban 3 grandes monolitos soberbios adornados en su superficie con esculturas que por su perfección artística no fueron inferiores a los relieves de Santa Lucía. Nos contaron que en la temporada en la que se llevaron las piedras grandes a Berlin el ingeniero Napp habia pensado en llevarse también éstas. Cambios de gobierno y protestas del dueño parecen haber evitado esto. En efecto muestran las piedras huellas de un trabajo iniciado con el fin de desfasar la superficie tallada. " (Seler 1900, p. 237)

"Pero aparte de las 3 estelas había 2 piedras más en este sitio. La gente siempre había llamado " mesa » a una y en efecto parecía su superficie grande, redonda y lisa una mesa. Como salía sólo un poco de la tierra empezamos a excavarla. Resultó que estaba bastante profunda dentro de la tierra y apareció un gran cangrejo de piedra. Además había una enorme y profundamente trabajada cabeza de reptil, la cual no estaba parada sino acostada. Así habiamos encontrado en una área pequeña seis bellas piedras. » (Ibid., p. 239) '
\end{abstract}

Por fortuna, la tarea de remover las superficies esculpidas de los monumentos 1-3 nunca se completó, a pesar de que las principales esculturas fueron extraídas del sitio antes de 1909. El viajero francés Maurice de Périgny las fotografió ese año, cuando yacían en una milpa de las afueras de la ciudad de Guatemala (Périgny 1911; Taladoire 1995). Périgny visitó el sitio y escribió un breve párrafo, en el que anotó la presencia de dos estelas lisas, más o menos rectangulares, todavía erguidas, una de las cuales alcanzaba tres metros de altura. El paradero de ambas piedras se desconoce.

La odisea de las esculturas no terminó allí. Poco después de la visita de Périgny, los monumentos 1-3 fueron trasladados al Museo de La Reforma en la ciudad de Guatemala, un hermoso edificio que fue totalmente destruido por los terremotos de 1917. Las estelas no resultaron dañadas, debido a que nunca fueron instaladas en el interior del museo, sino que permanecieron afuera, expuestas a los elementos, como lo atestiguó un viajero contemporáneo (Elliot 1924). Algún tiempo después fueron colocadas en el exterior del Observatorio Meteorológico, donde permanecieron hasta 1933, cuando fueron trasladadas al nuevo museo nacional inaugurado en 1930 en el parque La Aurora. Nuevamente, fueron colocadas fuera del edificio, frente a la puerta principal. Las estelas de Palo Verde no tuvieron el privilegio de entrar bajo techo sino hasta después de 1948, cuando se inauguró el actual edificio del museo nacional de arqueología y etnología, donde han permanecido en exhibición hasta el presente. En fecha desconocida, los monumentos 5 y 6 de Palo Verde fueron también trasladados a la ciudad de Guatemala, mientras que el monumento 4 pasó a formar parte de la colección del ingenio El Baúl. 


\section{Trabajos del Proyecto arqueológico Cotzumalguapa}

Después de la visita de Périgny, ningún arqueólogo estudió el sitio hasta 1994, cuando el primer autor de este artículo pudo localizarlo nuevamente gracias al reporte de Seler ${ }^{2}$. Durante la visita de 1994 se realizó un plano parcial del sitio (Chinchilla 1996a, p. 408), y se obtuvo una pequeña colección de cerámica. La enorme cantidad de cenizas volcánicas en la superficie restringió la posibilidad de recuperar una buena muestra de materiales de superficie, mientras que el mapeo se vio afectado por la escasa visibilidad de las estructuras, que se encontraban en un cafetal denso. Esta condición hizo apremiante el mapeo detallado del sitio cuando, a fines de 2000, un sobrevuelo permitió observar que el cafetal había sido podado, con lo que mejoró notablemente la visibilidad de las estructuras.

El mapeo topográfico se realizó con un teodolito electrónico Topcon DT-30, cubriendo un área de 2.2 hectáreas. Se colocaron 30 estaciones en polígonos cerrados, y a partir de ellas se obtuvo un total de 935 puntos de mapeo. Se utilizó un recolector de datos consistente en una calculadora científica Hewlett Packard HP-48GX dotada con una tarjeta de mapeo Tripod Data Systems COGO. Para el procesamiento final de los datos se utilizó el programa AutoCAD Land Development Desktop, que también facilitó la edición final del mapa topográfico y la elaboración de vistas tridimensionales (Figuras 2, 3, y 4).

El trabajo de esta temporada incluyó extensos recorridos y colecciones en los alrededores del sitio (Operación PV1). Aunque los materiales son escasos en general, fue posible obtener buenas muestras de superficie en algunos sectores, sobre todo en el área sembrada de caña de azúcar al este del conjunto principal. La prospección permitió estimar los límites norte, este y oeste del asentamiento. Un resultado casual fue el hallazgo del pequeño sitio de Versalles, situado en la finca del mismo nombre. Este hallazgo provee un primer atisbo de la posible existencia de un sistema de asentamientos menores alrededor del sitio.

Los reconocimientos se complementaron con entrevistas a los habitantes de las inmediaciones. Sin embargo, la región está muy poco poblada en la actualidad, y el conocimiento de la arqueología local se reduce a historias difíciles de verificar sobre el hallazgo de objetos especiales durante los trabajos agrícolas o de construcción. De hecho, ninguno de los entrevistados identificaba el sitio arqueológico como tal antes de nuestros trabajos.

Finalmente, se excavaron dos pozos estratigráficos, cuyos resultados se describen a continuación.

\section{EXCAVACIONES Y ESTRATIGRAFÍA}

El primer pozo se localizó en la parte central del sitio, al lado norte de la estructura 8. El segundo se colocó alrededor de $50 \mathrm{~m}$ al sureste de la estructura 9, en un sector actualmente cultivado con caña de azúcar (Figura 2). Esta localización fue escogida tomando en cuenta la concentración moderadamente alta de materiales recuperados en la superficie durante el reconocimiento, y proveyó una oportunidad 


\section{Pallo Verde}

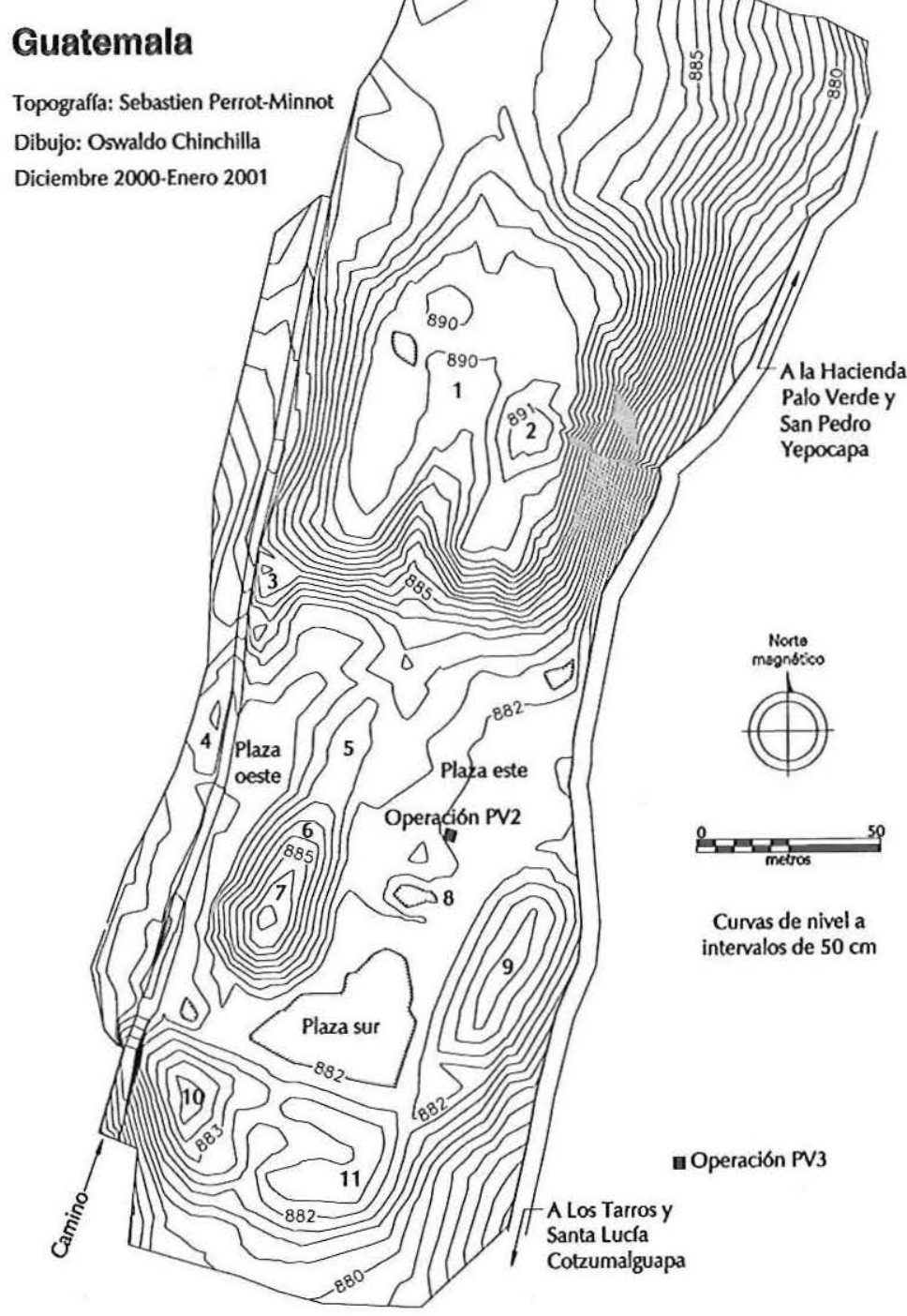

FIG. 2. - Mapa topográfico del sitio de Palo Verde. Elaborado por medio del programa AutoCAD Land Development Desktop, gentilmente donado por AutoCAD Guatemala/Geométrica SA

para comparar la estratigrafía de un sector aledaño al conjunto monumental con lo observado en la parte central del sitio, por medio de la operación PV2.

Con el objeto de controlar el derrumbe de las capas de ceniza volcánica reciente que cubren la superficie del sitio, ambos pozos se iniciaron con un área de $3 \times 3 \mathrm{~m}$, para luego reducirlos a $2 \times 2 \mathrm{~m}$. Este método funcionó eficientemente, pues el de- 


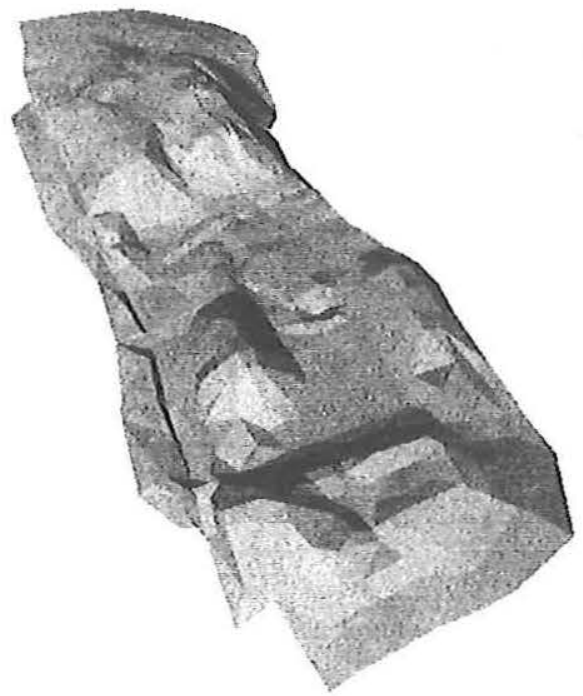

FIG. 3. - Vista tridimensional del sitio de Palo Verde. La parte superior de la gráfica está orientada hacia el noreste (AutoCAD)

rrumbe de las cenizas no cayó directamente dentro de la excavación. Ambos pozos se excavaron por medio de niveles artificiales de $20 \mathrm{~cm}$ de grosor, que cambiaron a niveles naturales al encontrar estratos claramente definidos.

\section{a. Operación PV2 (Figura 5)}

Situado en el lado norte de la estructura 8, este pozo se encontraba en un punto central del complejo arquitectónico del sitio, en terreno actualmente sembrado de café. Los estratos 1-9, hasta una profundidad máxima de $75 \mathrm{~cm}$ bajo la superficie, contenían cinco capas de cenizas volcánicas de textura variable, cuyo color oscilaba del gris al negro (estratos 1, 3, 5, 7 y 9). Separando las capas de ceniza había delgadas capas de tierra café, de 1 a $5 \mathrm{~cm}$ de grosor (estratos 2, 4, 6 y 8). Esto sugiere que cada capa fue el resultado de un evento eruptivo separado del anterior por un intervalo de tiempo más o menos prolongado, pero que al presente no podemos estimar. Sin embargo, todos estos estratos estaban exentos de materiales culturales, lo que sugiere que se depositaron después del abandono del sitio.

Debajo de las capas de cenizas superficiales se encontraron dos estratos de tierra suave (estratos 10 y 11), que en conjunto alcanzaron $60 \mathrm{~cm}$ de grosor, los cuales contenían artefactos en pequeñas concentraciones, posiblemente derivados de la erosión de las estructuras del sitio después de su abandono. Enseguida se encontraron otros estratos (12 al 15) de relleno duro, que alcanzaron un espesor máximo de $2.20 \mathrm{~m}$, y que contenían artefactos de cerámica y lítica en pequeñas cantidades. Estos estratos duros se interpretaron como el resultado de una gran obra de nivelación que se debió efectuar durante la construcción de las estructuras monumentales del sitio, la que posiblemente comprendió dos estadíos, correspondientes a los estratos 14 y 13. 


\section{Palo Verde}

\section{Guatemala}

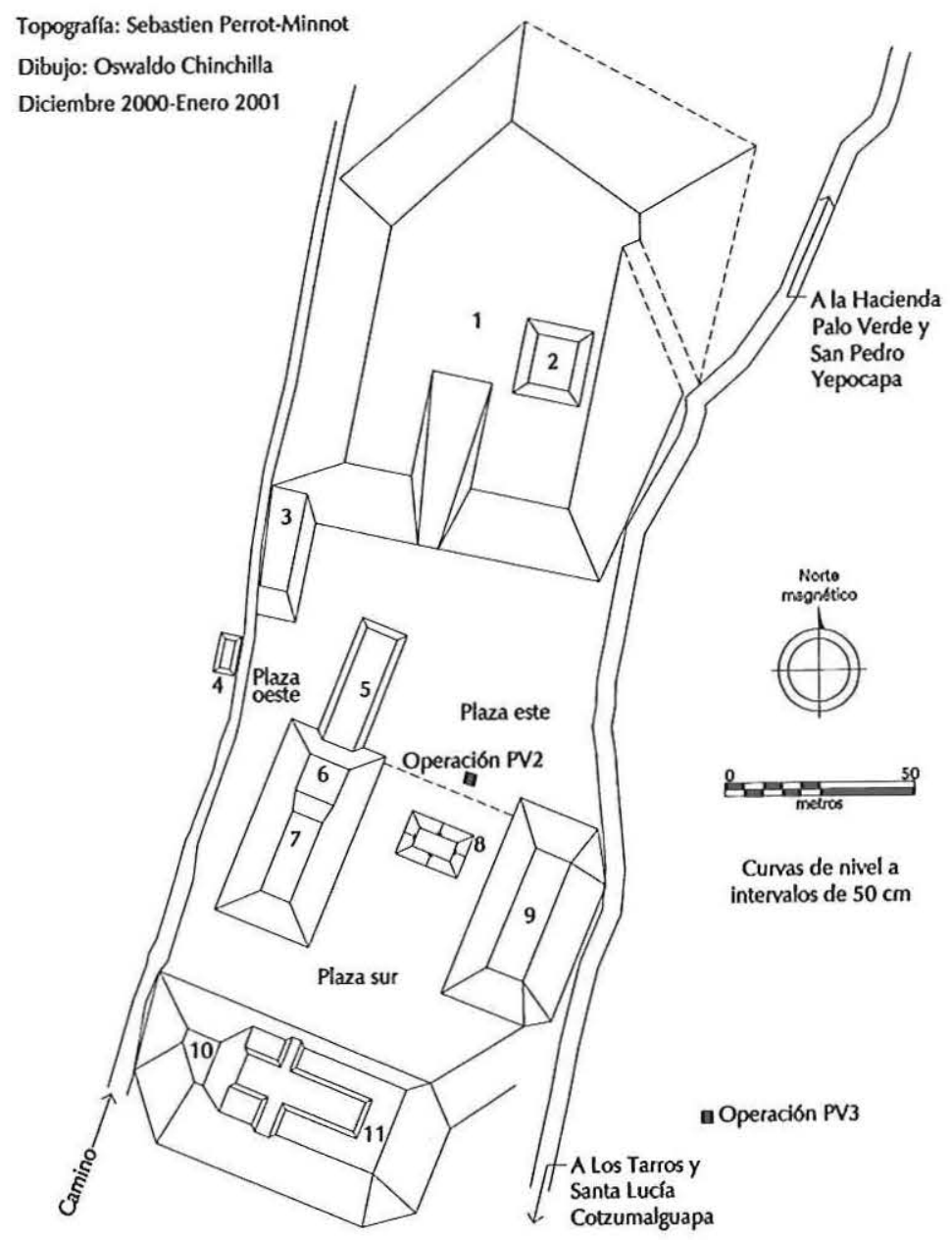

Fig. 4. - Mapa esquematico del sitio de Palo Verde (AutoCAD)

Se ignora la extensión horizontal de estos rellenos, pero su gran espesor sugiere que se invirtió un gran esfuerzo de trabajo para la adecuación del terreno donde se construyó el conjunto arquitectónico.

La concentración de materiales culturales se redujo drásticamente en la base del relleno duro, donde se encontró una bolsa de ceniza volcánica negra, a profundidad de $3.80 \mathrm{~m}$ bajo el datum. Esta ceniza seguramente se derivó de una erupción anterior a la construcción del sitio. Por debajo de este nivel se practicó una exploración de $50 \mathrm{~m}$ de diámetro que descendió hasta $4.84 \mathrm{~m}$ bajo la superficie sin encontrar materiales culturales. 
0.00 - Datum

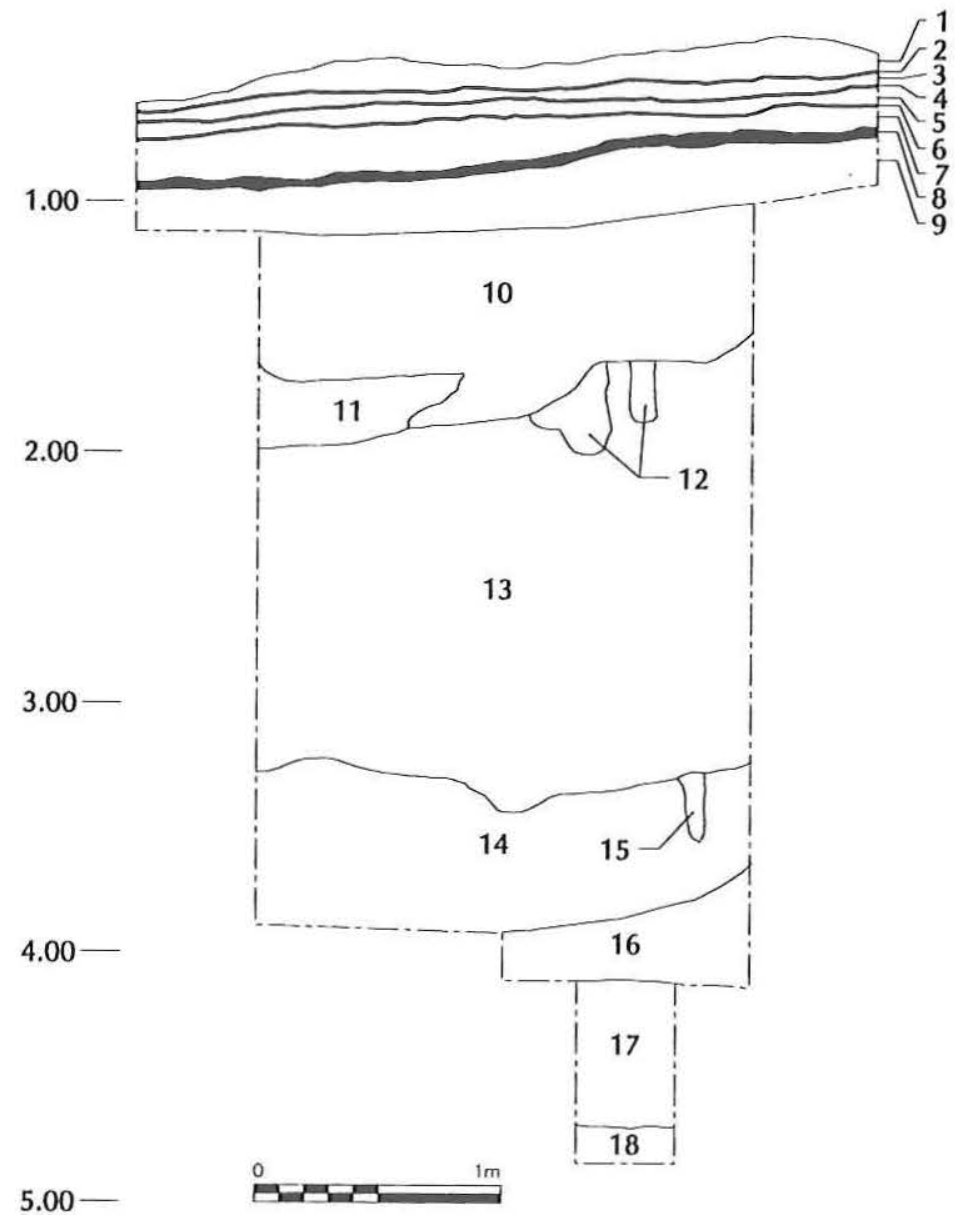

FIG. 5. - Operación PV2, perfil este : 1. Arena volcánica ; 2. Tierra café ; 3. Arena volcánica ; 4. Tierra café ; 5 . Arena volcánica ; 6. Tierra café; 7. Arena volcánica ; 8. Tierra café ; 9. Arena volcánica ; 10. Suelo café oscuro suave; 11 . Suelo café claro suave; 12 . Relleno café oscuro muy duro; 13 . Relleno café claro duro; 14. Relleno café claro muy duro; 15. Relleno café oscuro muy duro; 16. Arena volcánica ; 17 . Suelo café oscuro duro; 18 . Arena

La concentración de materiales culturales fue baja a lo largo de toda esta excavación. En total, se obtuvieron solamente 39 bordes, entre los que destacan los grupos cerámicos Favorita $(33 \%)$ y Esmeralda $(23 \%)^{3}$. La abundancia de Favorita y la baja presencia de vasijas de servicio es consistente con el carácter no doméstico del sector. Los materiales fueron casi exclusivamente de la fase Pantaleón (600-1000 d. C.), pero en los niveles inferiores se detectaron tiestos preclásicos, incluyendo un borde del grupo Acomé, del período preclásico terminal (0-200 d. C.). La actividad preclásica en el centro del sitio se confirma con el hallazgo de algunos tiestos de esta época en el 
relleno de la estructura 10. Estos se encontraron en el lado oeste de la estructura, donde la misma ha sido cortada por un camino moderno.

\section{b. Operación PV3 (Figura 6)}

Desde el inicio de la operación, se registraron concentraciones de cerámica y obsidiana mucho más altas que en la operación PV2, y al final se obtuvo una muestra de 298 bordes identificables. Aunque los depósitos superficiales (estratos 1 y 2) fueron arenosos, en este pozo no se definieron los estratos de cenizas volcánicas y capas de tierra que se describieron en PV2, posiblemente debido al disturbio ocasionado por el cultivo de la caña de azúcar. Alrededor de $1.00 \mathrm{~m}$ bajo el datum se observó un piso de barro apisonado formado por varias capas superpuestas. La concentración de cerámica se mantuvo alta por debajo de este nivel. La presencia de un basurero doméstico fue indicada por los materiales quemados y por la presencia más o menos equilibrada de grupos finos de servicio, tales como Tiquisate y Congo, en asociación con grupos de cerámica burda o intermedia, tales como Recuerdo Diamantes, Tarros y Esmeralda. Entre 2.75 y $3.15 \mathrm{~m}$ debajo del datum se encontró una serie de capas de material arenoso fino, alternando con tierra dura (estratos 6-11). La concentración de materiales se redujo drásticamente, pero se observó la presencia de tiestos del período preclásico medio (800-300 a. C.), que nuevamente demuestran la antigüedad de la ocupación del sitio. Este patrón estratigráfico parece indicar una etapa incipiente de ocupación preclásica seguida por una etapa de abandono, la cual quedó marcada por las capas naturales de cenizas volcánicas y suelos.

La excavación se detuvo a $3.60 \mathrm{~m}$ bajo el datum, pero se extendió por medio de una exploración de $50 \mathrm{~cm}$ de diámetro, que penetró hasta $4.30 \mathrm{~m}$ bajo la superficie. No se alcanzó un nivel completamente estéril, pero la concentración de materiales en la parte final de la excavación fue extremadamente baja.

En conjunto, las excavaciones permitieron obtener una primera impresión sobre la historia del sitio. Al parecer, tuvo una ocupación incipiente durante el preclásico medio y tardío ( 800 a. C.-200 d. C.). Se ignora la extensión espacial de esta ocupación, y tampoco se puede establecer si en estas fechas el sitio tenía el rango importante que adquirió durante el período clásico tardío y terminal (600-1000 d. C.). En esta época, se depositó una enorme cantidad de relleno, aparentemente con el propósito de nivelar la parte central del sitio. Es probable que esta nivelación haya precedido inmediatamente a la construcción de los edificios principales, pero será necesario estudiar la secuencia constructiva de los mismos para arribar a conclusiones seguras. El sitio fue abandonado al final del período clásico o inicios del Postclásico (alrededor del año 1000 d. C.).

Persiste duda sobre una posible ocupación postclásica del sitio. Entre los materiales superficiales y en las excavaciones se recuperó una moderada concentración de tiestos del grupo Santa Rita Micáceo, tradicionalmente fechado para el Postclásico tardío (Parsons 1967, pp. 157-158). Sin embargo, la ausencia de otros tipos diagnósticos de ese período permite dudar del fechamiento de estos materiales. Observaciones efectuadas en otros contextos en la zona de Cotzumalguapa sugieren que la cerámica micácea podría aparecer desde el Clásico terminal. 
0.00 - Datum

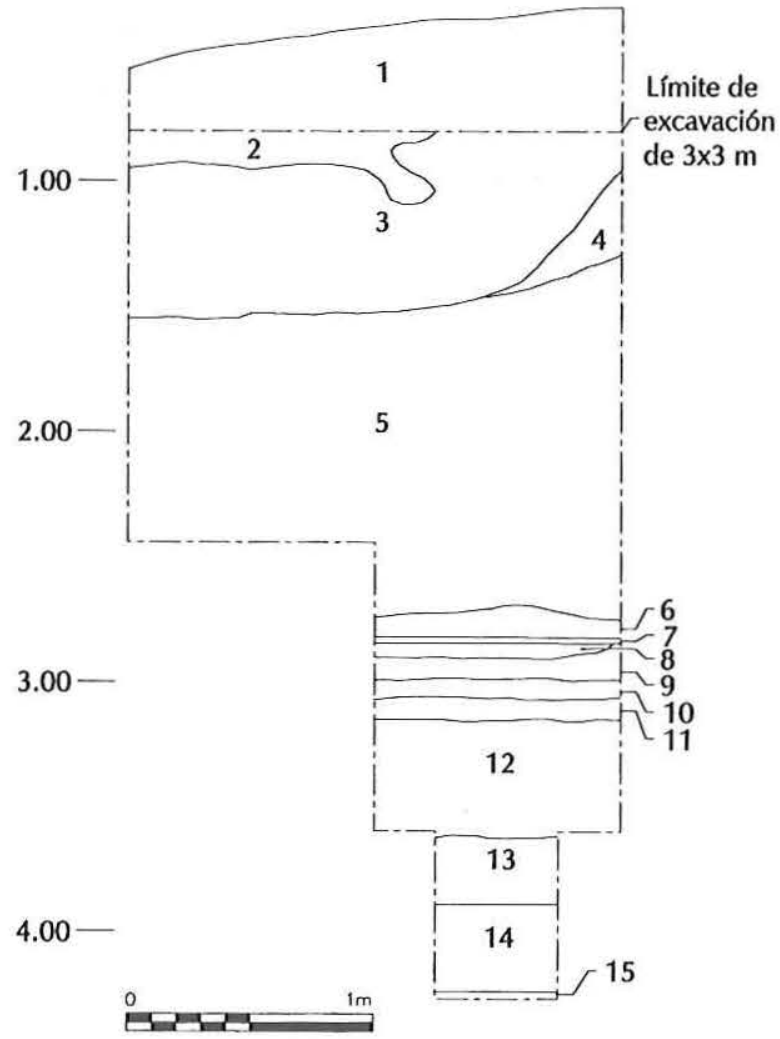

FIG. 6. - Operación PV3, perfil norte : 1. Suelo arenoso ; 2. Suelo arenoso ; 3. Tierra café amarillento ; 4. Suelo café claro ; 5 . Tierra café suave ; 6 . Arena ; 7-11. Capas alternadas de arena gris fina y suelo café ; 12. Tierra café claro; 13. Arena ; 14. Tierra con mezcla de ceniza ; 15 . Suelo café oscuro

\section{ARQUITECTURA Y URBANISMO}

El sector central del sitio (Figuras 2 y 3) ocupa una franja delgada de terreno elevado con leve pendiente de norte a sur. Los edificios cubren un área aproximada de 2 hectáreas, con una longitud máxima de $340 \mathrm{~m}$ de norte a sur, por $125 \mathrm{~m}$ de este a oeste. Es posible que algunas estructuras hayan sido destruidas por los caminos que actualmente delimitan el sitio en sus lados este y oeste. Al presente, todas se presentan como montículos de tierra cultivados con café. No se observan piedras en la superficie, por lo que será interesante comprobar si el sitio presenta un patrón arquitectónico diferente al de la Zona Nuclear de Cotzumalguapa, donde las estructuras de barro usualmente están revestidas con piedras escogidas, que también se utilizaron en escalinatas y pavimentos.

El sitio está dominado, en su lado norte, por una imponente plataforma que puede caracterizarse como una acrópolis (estructura 1). Mide alrededor de $140 \times 105 \mathrm{~m}$, y se 
eleva un máximo de $7 \mathrm{~m}$ con respecto a la plaza que se encuentra al lado sur. En este lado presenta dos brazos, separados entre sí por una gran rampa, que posiblemente daba acceso al conjunto. En el lado este de la plataforma parece haber otra rampa estrecha que sube hacia la esquina noreste. Es probable que también haya un acceso en el lado norte de la plataforma, que se extiende en la parte central formando una marcada prolongación. La superficie de esta acrópolis es esencialmente plana, y no se distinguen restos de los edificios individuales que seguramente se elevaban sobre ella, con excepción de la estructura 2. Este montículo se alza $1 \mathrm{~m}$ por encima del nivel de la estructura 1, y constituye el punto más alto del sitio. En su esquina suroeste, la estructura 1 se prolonga hacia el sur por medio de la estructura 3, delimitando parcialmente la plaza oeste.

Las estructuras 5-7 conforman una estructura alargada cuya altura decrece hacia el norte, formando tres niveles. La localización de estas estructuras es de particular interés, pues pareciera romper con el patrón arquitectónico definido por la estructura 1 . En vez de alinearse con la estructura 3 para dejar abierta una plaza más amplia, las estructuras 5-7 están alineadas con la rampa central de la estructura 1, y parecen extenderse hacia ella. De ese modo, las estructuras 5-7 se encuentran en un eje central que separa las plazas oeste y norte.

La plaza oeste es un espacio pobremente definido, atravesado por el moderno camino de la finca, que corta el lado oeste de la estructura 3. Esta plaza está delimitada por las estructuras $1,3,4$ y 5 . Por su parte, la plaza este está delimitada por las estructuras 1, 5, y 8, y está cortada por el camino que conduce a San Pedro Yepocapa, el cual corre en su lado este. Es probable que el profundo corte de este camino haya destruido estructuras que se encontraban en este sector.

La estructura 8 separa las plazas este y sur de Palo Verde. Por sus rasgos superficiales, esta estructura puede caracterizarse como un pequeño patio hundido, con aparente orientación de este a oeste. La localización de este aparente patio hundido en medio de las dos plazas es intrigante.

La plaza sur está delimitada al este por la estructura 9, un montículo alargado que corre paralelo a las estructuras 5-7. En el lado sur de la plaza se encuentran las estructuras 10-11, que forman el límite sur del conjunto arquitectónico principal. Estas estructuras forman una palangana dominada por un montículo de $4 \mathrm{~m}$ de alto en el lado oeste, el cual ha sido cortado por el camino moderno. Esta palangana presenta dos entradas alineadas en su eje central, lo que constituye un rasgo muy poco usual en este tipo de edificios.

Un detalle de interés concierne a la orientación de las estructuras. El mapeo topográfico reveló que la gran plataforma de las estructuras 1,2 y 3 tiene una orientación aproximada de $12^{\circ}$ este, mientras que los edificios de la parte sur del sitio, incluyendo las estructuras 5-11, están orientados aproximadamente a $22^{\circ}$ este. Esta variación de $10^{\circ}$ en la orientación de las estructuras perceptible en la superficie actual del sitio puede ser significativa en términos constructivos o simbólicos, pero deberá confirmarse por medio de excavaciones en ambos sectores.

Los recorridos efectuados alrededor del sitio revelaron que los asentamientos se extienden especialmente hacia el este y sureste del sitio. Es posible que esta observación esté afectada por las condiciones de uso de la tierra, pues el terreno al este se encuentra sembrado con caña de azúcar, y sujeto periódicamente a la acción del 
arado. En contraste, la parte central y oeste está cubierta con cafetales y bosques. Sin embargo, debe considerarse también que el sector oeste es más quebrado, y presenta pendientes fuertes. En contraste, el sector al este del sitio, en terrenos de la finca Versalles, ofrece terrenos con pendientes más suaves. Por tanto, es probable que las mayores densidades de materiales recuperados allí reflejen un patrón real.

Desde un punto de vista comparativo, la disposición general de las estructuras principales de Palo Verde guarda alguna semejanza con el sitio de El Baúl. Ambos cuentan con una gran plataforma o acrópolis en su lado norte, que domina un conjunto situado a nivel más bajo en la parte sur. Sin embargo, la disposición de las estructuras en la parte sur de Palo Verde se aparta del patrón observado en El Baúl, el cual se caracteriza por presentar grandes recintos cerrados (Chinchilla 1998).

\section{El Sitio De Versalles}

El pequeño sitio de Versalles está situado aproximadamente $800 \mathrm{~m}$ al sur del conjunto central de Palo Verde. El recorrido de superficie reveló materiales en toda la extensión de terreno entre ambos sitios, por lo que puede considerarse como parte integrante del sistema de asentamientos centrado en Palo Verde. Es posible que existan otros conjuntos similares en el entorno, que no fueron detectados.

El sitio (Figura 7) consiste de una plazuela rodeada por al menos dos estructuras, que cierran sus lados norte y oeste. Hay indicios de una tercera estructura en el lado sur, y es posible que existan otras en la pendiente al noroeste de la plaza. Es muy probable que las cenizas depositadas a lo largo de los siglos hayan ocultado otras estructuras. El conjunto se encuentra en un terreno con marcada pendiente, y está atravesado por un camino moderno. El conjunto cubre un área aproximada de $3000 \mathrm{~m}^{2}$, y su orientación aparente es de $324^{\circ} \mathrm{Az}$. La recolección de superficie produjo principalmente materiales del período clásico tardío con una posible ocupación postclásica indicada por la presencia de Santa Rita Micáceo.

Versalles corresponde bien con el patrón observado en sitios de rango terciario en el sistema de asentamientos del período clásico tardío, centrado en la Zona Nuclear de Cotzumalguapa (Chinchilla 1996a, pp. 439-441). Estos sitios están conformados por pequeñas plazas cuadrangulares rodeadas por estructuras pequeñas. La estructura mayor suele estar situada en el lado norte de la plaza, lo que parece cumplirse en el caso de Versalles.

\section{Las esculturas de Palo Verde}

Seler (1900) ilustró en su reporte seis esculturas, que han sido publicadas repetidamente (Thompson 1948, Figura 6; Willey 1966, Figura 3-101 ; Parsons 1969, lámina 35 ; Greene et al. 1972, pp. 420-423). A la vez, mencionó otras piezas del sitio que habían sido trasladadas al patio de la finca Palo Verde, entre las que destacaba una cabeza de jaguar de piedra (Seler 1900, p. 321). Este dato fue confirmado en el año 2000 por la Sra. Etelvina Catalán, residente de Santa Lucía Cotzumalguapa, y nieta del antiguo propietario de Palo Verde, el Sr. Secundino Morales, cuya propiedad abarcaba las actuales fincas El Tigre y Giralda. Según la Sra. Catalán, tres esculturas 


\section{Versalles Guatemala}

Mapeo: Sébastien Perrot-Minnot

Dibujo: Oswaldo Chinchilla

Enero 2001

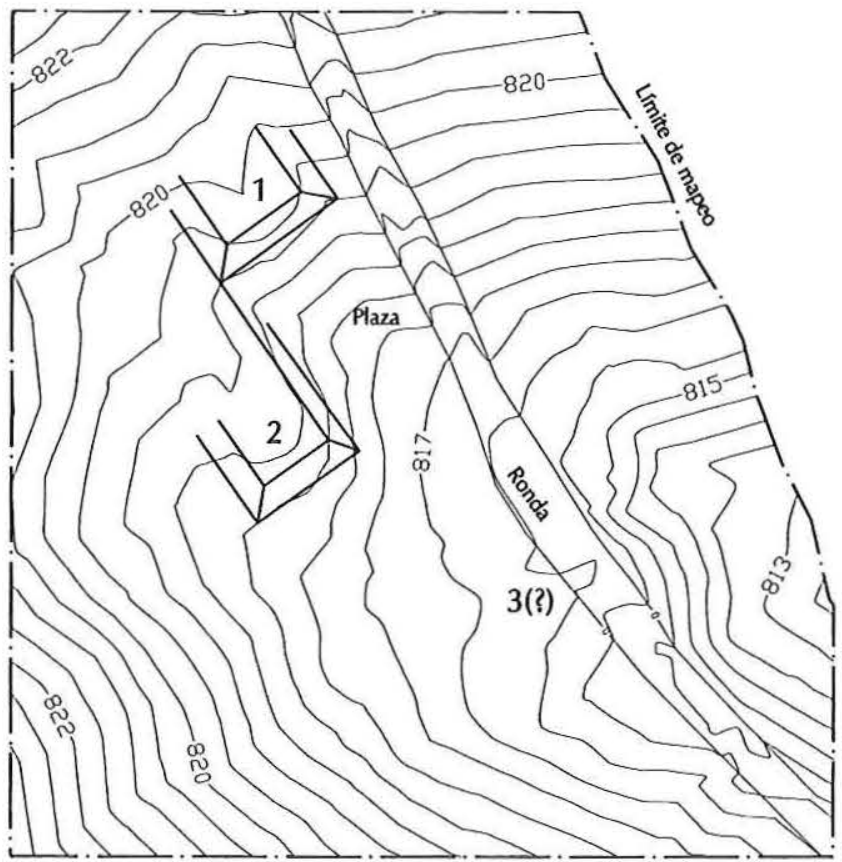

Norte
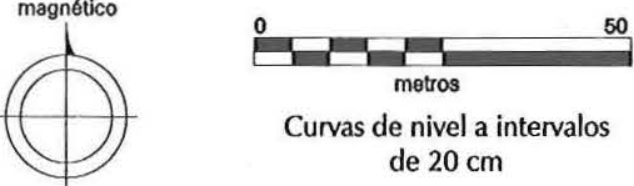

Curvas de nivel a intervalos de $20 \mathrm{~cm}$

Fig. 7. - Mapa topográfico del sitio arqueológico de Versalles (AutoCAD)

servían como bases para las pilastras de la cárcel de la finca. Dos de ellas representaban cabezas de tigre y la tercera, un tigre de cuerpo entero. En fecha no determinada, el jefe político del departamento de Chimaltenango se llevó una, y posteriormente, una tía trasladó la otra a la Antigua Guatemala. Se ignora el paradero actual de estas piezas, y también se ignora el paradero de dos estelas lisas observadas por Périgny (1911).

La tercera escultura que estaba en la cárcel de Palo Verde es el monumento 7, actualmente propiedad de la Sra. Catalán, quien gentilmente permitió fotografiarlo. Es posible que esta sea la cabeza de jaguar mencionada por la señora Seler. El monumento 7 (Figura 8) es una cabeza colosal que mide $65 \mathrm{~cm}$ de altura, $80 \mathrm{~cm}$ de 

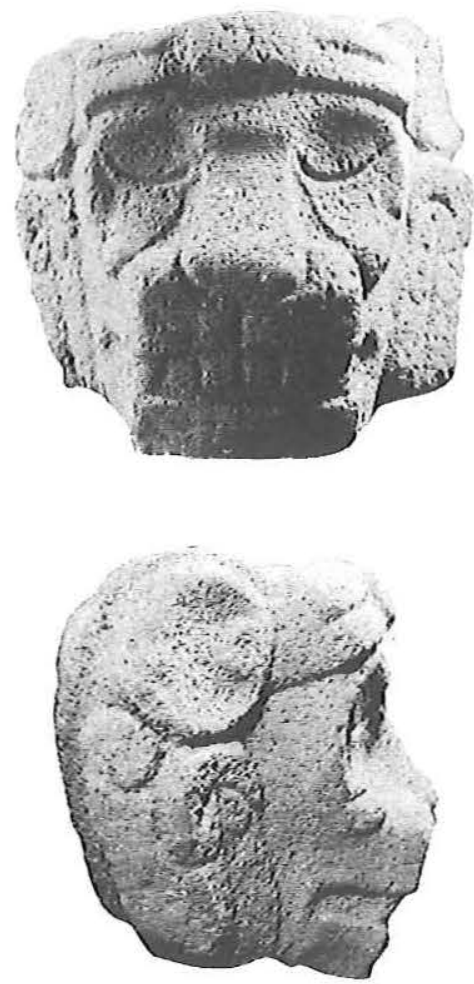

FIG. 8. - Monumento 7 de Palo Verde, vista frontal y lateral. Dimensiones : alto $65 \mathrm{~cm}$, ancho $80 \mathrm{~cm}$, grossor $55 \mathrm{~cm}$. Foto: O. Chinchilla

ancho y $55 \mathrm{~cm}$ de grosor. Representa un jaguar con la boca entreabierta, que porta una diadema de tela, anudada sobre la frente. Debajo de sus redondas orejas lleva orejeras que consisten en trozos de tela que penden del centro de un elemento circular. El jaguar se distingue especialmente por sus ojos cerrados, de los que cuelgan las pupilas desorbitadas. Este rasgo se repite en figuras humanas y mitológicas procedentes de El Baúl y Pantaleón (Vreeland y Bransford 1885 ; Chinchilla 1996b). El monumento 7 presenta una curiosa perforación rectangular en la parte superior ; de acuerdo con la Sra. Catalán se le hizo para insertar el pilar de la cárcel.

A las siete esculturas monumentales conocidas puede agregarse una escultura menor, que actualmente para en poder del Sr. Fernando Mejicanos, en Santa Lucía Cotzumalguapa (Figura 9). El actual propietario informó que la escultura fue encontrada por su padre hace unos quince años, mientras trabajaba en la finca El Tigre, es decir, en los terrenos que se extienden inmediatamente al este y sureste del sitio de Palo Verde. Esta pequeña escultura mide $35.5 \mathrm{~cm}$ de alto, $16 \mathrm{~cm}$ de ancho y $10 \mathrm{~cm}$ de grosor. Representa un tigre sedente, cuya actitud es muy similar a la de los monumentos 86 de Bilabo y 14 de El Baúl, este último una de las esculturas más hermosas del estilo Cotzumalguapa ${ }^{4}$. La talla es fina, especialmente la cabeza, desproporcionadamente grande, que se caracteriza por su boca ampliamente abierta, y por sus orejas en 

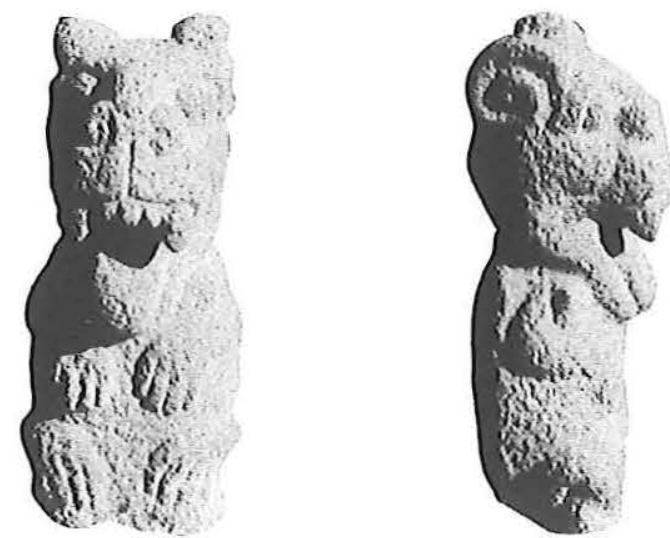

FIG. 9. - Escultura portátil procedente de la Finca Versalles. Vista frontal y lateral. Dimensiones : alto $35,5 \mathrm{~cm}$, ancho $16 \mathrm{~cm}$, grosor $10 \mathrm{~cm}$. Foto : $\mathrm{O}$. Chinchilla

forma de espiral. El cuerpo es mucho más simple; los brazos y piernas aparecen apenas esbozados y carece de cola.

No conocemos el contexto preciso del descubrimiento de ninguna de las esculturas de Palo Verde, lo que impide analizarlas en relación con la arquitectura monumental del sitio. Podemos afirmar solamente que Palo Verde posee uno de los mayores y más notables conjuntos de esculturas en el estilo Cotzumalguapa. Aunada a la arquitectura monumental, la riqueza escultórica del sitio es un indicador de su importancia dentro del sistema de asentamientos del Clásico tardío, centrado en la Zona Nuclear de Cotzumalguapa. Cabe destacar algunos paralelos importantes entre los monumentos del sitio y el corpus de la Zona Nuclear.

Los monumentos 1-3 de Palo Verde (Figuras 10-12) han llamado la atención por su gran similitud temática con los monumentos 2-8 de Bilbao. Al igual que estos, las tres estelas de Palo Verde representan individuos de perfil, que elevan ofrendas. Aunque se han omitido solamente los seres superiores que aparecen en la parte alta de los monumentos 2-8 de Bilbao, la similitud es clara, y ha sido señalada por otros autores (Thompson 1948, p. 19 ; Parsons 1969, p. 109). Ambos conjuntos escultóricos comparten no solamente el tema, sino también el formato. Las estelas se caracterizan por su forma rectangular ( 2.30 a $2.38 \mathrm{~m}$ de alto y 65 a $68 \mathrm{~cm}$ de ancho), su superficie superior plana, y su grosor substancial. Este formato casi columnar es muy similar al de los monumentos 1-8 de Bilbao, y no se repite en ninguna otra escultura del corpus de Cotzumalguapa. La similitud en forma y contenido hace pensar que los monumentos 1-3 de Palo Verde representaron una emulación consciente del conjunto escultórico de Bilbao, que entonces como ahora debió ser uno de los más renombrados de Cotzumalguapa.

El monumento 4 (Figura 13) es una escultura en bulto que representa un cangrejo con la cabeza de un monstruo reptilino (Chinchilla 1996a, pp. 118-122). El tema del cangrejo, por demás raro en el arte mesoamericano, aparece en otras esculturas de la región de Cotzumalguapa (monumentos 1, 7, y 18 de Bilbao, y 7 de El Baúl). La parte superior de esta escultura es totalmente plana, lo que sugiere que debió servir ya sea 


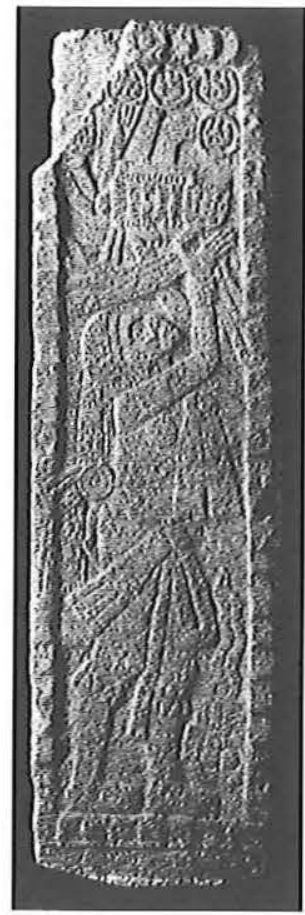

10

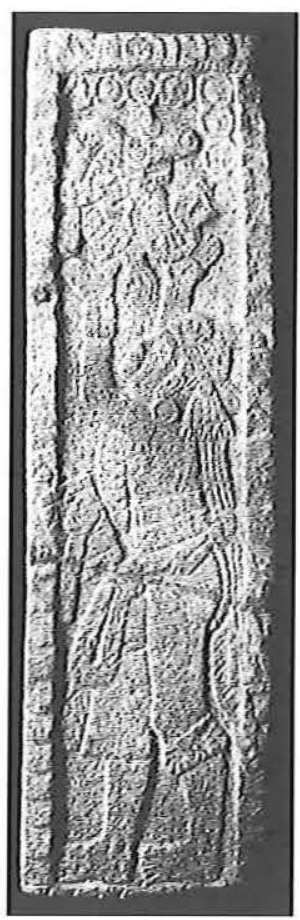

11

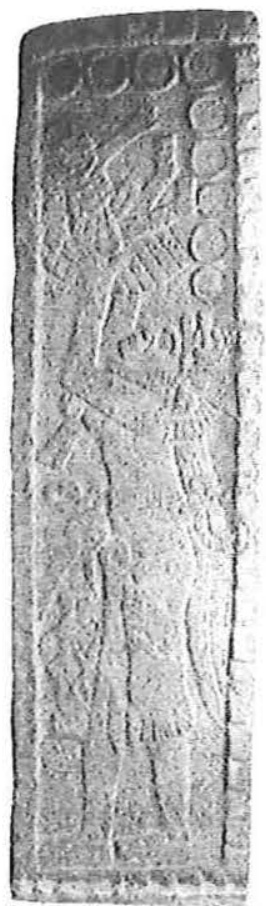

12

Fig. 10. - Monumento 1 de Palo Verde. Dimensiones : alto $238 \mathrm{~cm}$, ancho $68 \mathrm{~cm}$. Foto: D. Chauche, cortesía de Fundación G \& T.

Fig. 11. - Monumento 2 de Palo Verde. Dimensiones : alto $230 \mathrm{~cm}$, ancho $65 \mathrm{~cm}$. Foto: D. Chauche, cortesía de Fundación G \& T.

Fig. 12. - Monumento 3 de Palo Verde. Dimensiones : alto $233 \mathrm{~cm}$, ancho $66 \mathrm{~cm}$. Foto : O. Chinchilla

para colocar objetos especiales, o quizás como asiento o trono. El monumento 5 (Figura 14) es una escultura en bulto que representa la cabeza del monstruo reptilino, un ser mítico ampliamente difundido en el arte mesoamericano, afiliado con el conjunto de imágenes que Taube (1992) identifica como la « serpiente de guerra », de origen teotihuacano (Chinchilla 1996a, pp. 118-122). El monumento 5 lo representa en una forma típica, que se repite en numerosas esculturas del altiplano y costa sur de Guatemala (véase Thompson 1948, Figura 14 ; Parsons 1986, láminas 204-209). Al combinar la cabeza del monstruo con un cuerpo de cangrejo, el monumento 4 ejemplifica la forma en que el arte de Cotzumalguapa retomó y reinterpretó este y otros motivos panmesoamericanos.

Caracterizado por los autores más tempranos como « jaguar », el monumento 6 (Figura 15) es una escultura en bulto que representa un ser mítico de gran interés. Combina elementos físicos de varios animales. Por la forma de sus piernas y sus largas uñas, el cuerpo pareciera ser de iguana, aunque carece de la cresta típica de este animal. La cabeza parece serpentina, por su lengua bífida y sus largos colmillos 


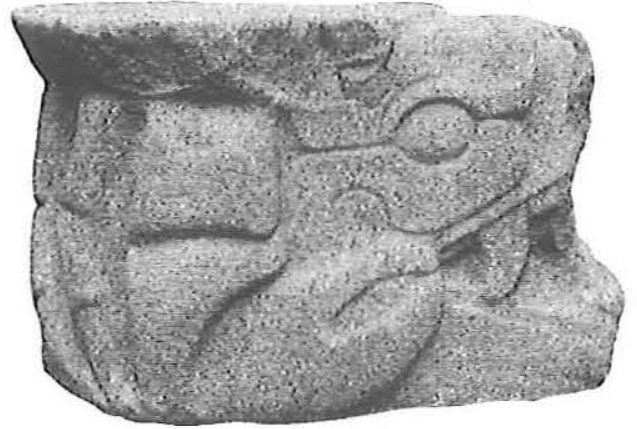

13
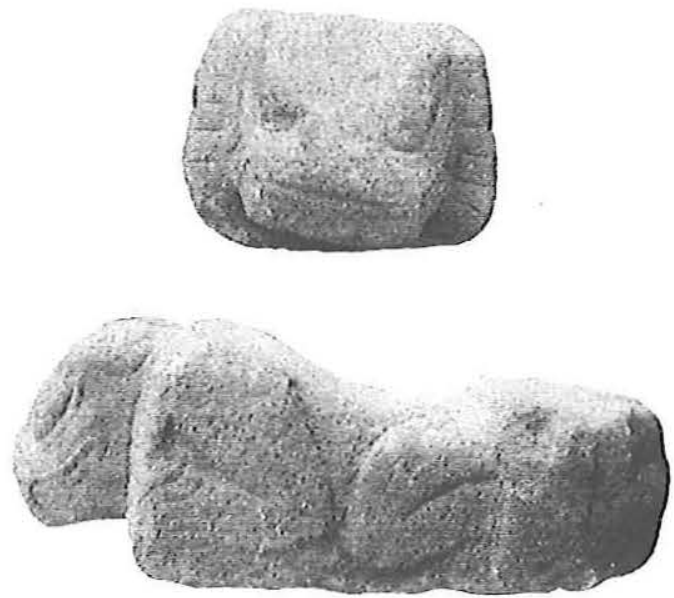

15

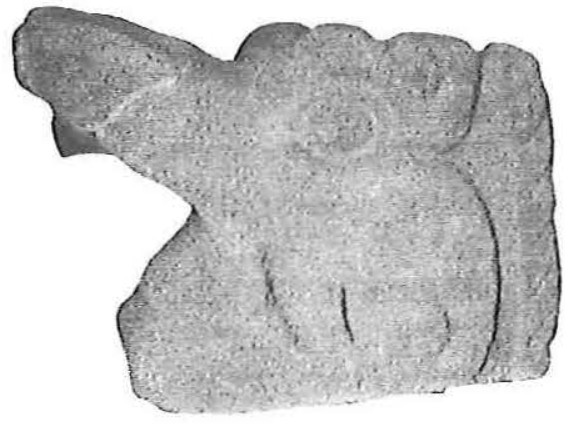

14

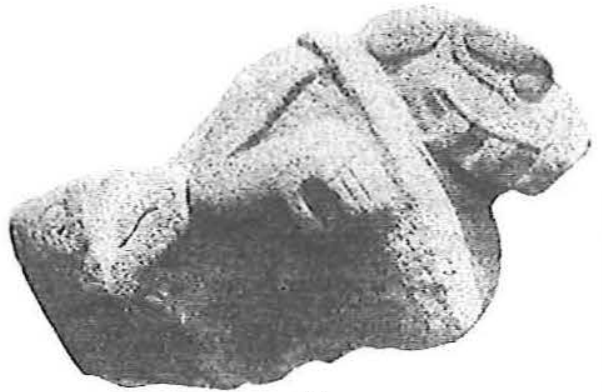

16

FIG. 13. - Monumento 4 de Palo Verde, vista lateral. Dimensiones : alto $58 \mathrm{~cm}$, ancho $73 \mathrm{~cm}$, grosor $92 \mathrm{~cm}$. Foto: O. Chinchilla

FIG. 14. - Monumento 5 de Palo Verde. Dimensiones: alto $61 \mathrm{~cm}$, ancho $51 \mathrm{~cm}$, grosor $61 \mathrm{~cm}$. Foto : O. Chinchilla

FIG. 15. - Monumento 6 de Palo Verde. Dimensiones : alto $46 \mathrm{~cm}$, ancho $58 \mathrm{~cm}$, largo $120 \mathrm{~cm}$. Foto: O. Chinchilla

Fig. 16. - Escultura de la zona de Santa Lucía Cotzumalguapa, actualmente en el Museo de La Democracia, Escuintla. Dimensiones : alto $55 \mathrm{~cm}$, ancho $70 \mathrm{~cm}$, largo $130 \mathrm{~cm}$. Foto : O. Chinchilla

puntiagudos. Lleva el collar característico de muchas representaciones de animales en el arte de Cotzumalguapa. Finalmente, la cola representa un cascabel de serpiente. El mejor ejemplo de este tema se encuentra en el monumento 26 de El Baúl (Parsons 1969 , p. 133), y también se conoce otra escultura similar que posiblemente venga del mismo sitio ${ }^{5}$ (Figura 16). En los alrededores de la Zona Nuclear, se presenta en el monumento 6 de Palo Verde y el monumento 1 de Xatá (Thompson 1948, Figura 17f). Es llamativa la uniformidad de este grupo de representaciones; aunque varían en su calidad escultórica, todas mantienen el formato tridimensional y esencialmente los mismos parámetros en la representación del tema. El monumento de Xatá se diferencia solamente por presentar una depresión en el dorso, que lo convierte 
en un recipiente. La uniformidad del grupo se hace mayor al observar que no se conoce ninguna representación de este ser mítico en relieves u otros formatos escultóricos.

En resumen, el conjunto escultórico de Palo Verde contiene ejemplos de escultura de primer orden, que encuentran estrechos paralelos en la Zona Nuclear de Cotzumalguapa. El corpus escultórico de Palo Verde es con mucho, el más importante de entre los sitios que rodean a la Zona Nuclear. El punto de comparación más cercano se encuentra en Aguná, sitio localizado al suroeste de la Zona Nuclear, aproximadamente a la misma distancia que Palo Verde. Aguná compite con Palo Verde y lo sobrepasa en términos de su volumen constructivo (Chinchilla 1996a, pp. 411-414). Se conocen ocho esculturas procedentes de Aguná (Thompson 1948; Parsons 1969, p. 136 ; Chinchilla 1996a, p. 414), pero su tamaño, calidad artística y contenido iconográfico son inferiores a las de Palo Verde. En términos de su arte escultórico, Palo Verde se presenta como un sitio mucho más próximo al núcleo de la tradición artística centrada en la Zona Nuclear.

\section{LOS ARTEFACTOS}

Se ha discutido ya el significado cronológico de los materiales cerámicos. Otros artefactos recuperados incluyen fragmentos de figurilla, especialmente en la operación PV3, que produjo once fragmentos. Resta por analizar el material lítico, que incluyó un importante conjunto de fragmentos de obsidiana con navajas, lascas, algunas puntas, y posiblemente un fragmento de núcleo. Observaciones preliminares indican que estos materiales se derivan de las fuentes de El Chayal y San Martín Jilotepeque. La prospección de superficie también reveló un metate entero trípode, dos fragmentos de metates sin pies, cinco manos y varios fragmentos de manos lenticulares. Un fragmento de mano lenticular fue encontrado en un contexto del Clásico tardío, en la excavación 2.

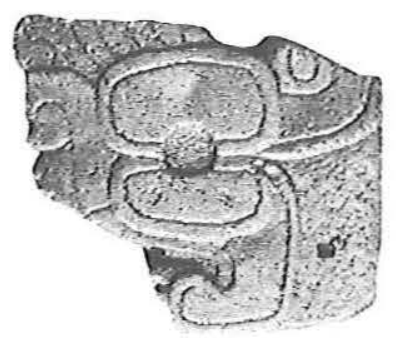

FIG. 17. - Fragmento de hacha procedente de la finca Giralda

La Figura 17 muestra un fragmento de hacha con forma de cabeza de serpiente, fotografiada en poder de un campesino local, quien afirmó que la había encontrado en la finca Giralda. Las hachas en forma de culebras no son numerosas (Shook y Marquis 1996, pp. 172-174). Por la presencia de lo que parecen ser plumas, guarda alguna similitud con los ejemplares S2 y S10 del catálogo de Shook y Marquis, procedentes respectivamente de Tulumaje (valle del río Motagua) y El Salvador. 


\section{CONCLUSIón}

Los trabajos de esta temporada proveen un primer acercamiento al sitio de Palo Verde. El registro de la arquitectura del sitio ha confirmado lo que parecía evidente a juzgar por sus esculturas : el sitio es uno de los mayores en el entorno de la Zona Nuclear de Cotzumalguapa, y se sitúa como uno de los dos centros de rango secundario en la jerarquía de asentamientos del período clásico (Chinchilla 1996a).

Los materiales cerámicos recuperados han indicado una ocupación incipiente en el Preclásico medio y tardío. A esta etapa siguió un período de abandono que se prolongó a lo largo del período clásico temprano. El principal desarrollo tuvo lugar durante el Clásico tardío y terminal, y coincide bien con el florecimiento de la Zona Nuclear de Cotzumalguapa. Parece obvio que el auge de Palo Verde fue estimulado por el crecimiento de la Zona Nuclear y, tal como se observó anteriormente, el conjunto escultórico del sitio sugiere una relación muy estrecha con la metrópoli. El gran relleno arquitectónico detectado en la operación PV2 sugiere que la construcción del centro monumental del sitio fue un evento planificado, para el que se contó con una gran disponibilidad de mano de obra. Cabe especular que esta obra monumental haya sido planeada y dirigida por los señores de la Zona Nuclear.

Quedan muchas preguntas por resolver en cuanto a la función del sitio y su relación con Cotzumalguapa. Es probable que Palo Verde haya servido como un centro de control para la región situada al norte de Cotzumalguapa, y quizás debió parte de su importancia al control de la ruta hacia el altiplano. Sin embargo, la posición geográfica del sitio es desconcertante por su cercanía al volcán de Fuego y el río Pantaleón, que dificultan considerablemente el uso de esa vía. Se señaló también el carácter potencialmente defensivo del sitio, que podría haber determinado en parte su localización. En el futuro una investigación geoarqueológica en el sitio y su entorno podría proveer claves importantes para la solución de estos problemas.

\section{Agradecimientos}

Las investigaciones en Palo Verde fueron financiadas por la Foundation for the Advancement of Mesoamerican Studies (FAMSI, grant 99053) y el Museo Popol Vuh, Universidad Francisco Marroquín, que también proporcionó espacio de laboratorio. Las gráficas se elaboraron por medio de programas gentilmente donados por AutoCAD Guatemala/Geométrica S.A. Deseamos agradecer la colaboración de los propietarios y el personal de las fincas El Baúl, Los Tarros y Pantaleón, y especialmente a los señores Eduardo Cucalón, Ricardo Díaz Durán y Fausto Chicas. La ayuda desinteresada de los señores Lionel Maltés y Etelvina Catalán, de Santa Lucía Cotzumalguapa, hizo posible documentar el monumento 7. Deseamos agradecer también el apoyo del Centro Francés de Estudios Mexicanos y Centroamericanos, dirigido en Guatemala por la Dra. Véronique Gervais. Por su participación en los trabajos agradecemos a Adriana Segura, Lionel Urizar, Luis Armando Linares, y Roger Herrera. El apoyo de Andrea Terrón fue de gran valor para preparar las ilustraciones. Finalmente, agradecemos la valiosa asesoría del Dr. Eric Taladoire y el Dr. Frederick J. Bove. 


\section{NOTAS}

1. Traducido por Oswaldo Chinchilla.

2. En 1937, H. E. D. Pollock visitó Palo Verde, de acuerdo con sus notas de campo, actualmente depositadas en los archivos del Museo Peabody, Universidad de Harvard. Pollock no publicó un reporte sobre esta visita, y sus notas no contienen más que una breve mención del sitio.

3. Los nombres de los grupos cerámicos se basan en el reporte de Parsons (1967), con extensas modificaciones que se describen con detalle en el reporte sobre la cerámica de la costa sur, actualmente en proceso de preparación por Frederick Bove y sus colaboradores.

4. Varios autores han fechado el monumento 14 de El Baúl para el período preclásico (Thompson 1948 , p. 31 ; Easby y Scott 1970 ; Parsons 1986 , p. 53). Esta opinión ha sido refutada por Chinchilla (1996a , p. 106). En particular, la presencia del collar anudado al frente coloca a esta escultura dentro del patrón más característico de las representaciones de animales en el estilo clásico tardío de Cotzumalguapa.

5. Este monumento fue trasladado al Museo arqueológico de La Democracia, Escuintla, en 1997. De acuerdo con informes orales, fue encontrada en una urbanización cercana a Santa Lucía Cotzumalguapa. Es posible que se trate de la colonia Maya, que en 1996 creció hasta afectar seriamente la parte sur del sitio de El Baúl.

\section{BIBLIOGRAFIA}

Bastian, A., 1878. - Ein Jahr auf Reisen. Kreuzfahrten zum Sammelbehuf auf Transatlantischen Feldern der Ethnologie. Die Culturländer des Alten America, vol. 1, Weidmannsche Buchhandlung, Berlin.

Chinchilla Mazariegos, O., 1996a. - Settlement Patterns and Momumental Art at a Major Pre-Columbian Polity : Cotzumalguapa, Guatemala, Doctoral Dissertation, Vanderbilt University, University Microfilms International, Ann Arbor, Michigan.

—, 1996b. — " "Peor es Nada": El Origen de las Esculturas de Cotzumalguapa ", in : Museum für Völkerkunde, Baessler Archiv, Neue Folge 44, pp. 295-358, Berlin.

—, 1996c. — « Las Esculturas de Pantaleón, Escuintla », U-Tz’ib 1, n 10, pp. 1-23, Asociación Tikal, Guatemala.

—, 1998. — «El Baúl : un sitio defensivo en la zona nuclear de Cotzumalguapa », in : XI Simposio de Investigaciones Arqueologicas en Guatemala, J. P. Laporte \& H. Escobedo (ed.), Instituto de Antropología e Historia de Guatemala/Asociación Tikal, Guatemala.

-, 2001. - Archaeological Research at Cotzumalguapa, Guatemala, página de internet: http ://www.famsi.org/reports/chinchilla/chinchilla2.htm.

Davies, D. K., R. K. Vessell, R. C. Miles, \& M. G. Foley, 1978. - « Fluvial transport and downstream sediment modifications in an active volcanic region ", in : Fluvial Sedimento$\log y$, A. D. Miall (ed.), pp. 61-84, Memoir 5, Canadian Society of Petroleum Geologists, Calgary .

EASBy, E. K. \& J. F. ScotT, 1970. - Before Cortés : Sculpture of Middle America, The Metropolitan Museum of Art, New York.

Ellıot, L. E., 1924. - Central America : New Paths in Ancient Lands, Methuen \& Co. Ltd, London. 
Gonzáles Quezada, C., 1974. - Monografia de Santa Lucía Cotzumalguapa, Colección Monografías 12, Editorial " José de Pineda Ibarra », Guatemala.

Greene, M., R. F. Heizer, \& J. A. Graham, 1972. - Maya Sculpture from the Southern Lowlands, the Highlands, and the Pacific Piedmont. Guatemala, Mexico, Honduras, Lederer, Street \& Zeus, Berkeley.

Parsons, L. A., 1967. - Bilbao, Guatemala: An Archaeological Study of the Pacific Coast Cotzumalhuapa Region, vol. 1, Publications in Anthropology 11, Milwaukee Public Museum, Milwaukee.

-, 1969. - Bilbao, Guatemala : An Archaeological Study of the Pacific Coast Cotzumalhuapa Region, vol. 2, Publications in Anthropology 12, Milwaukee Public Museum, Milwaukee.

—, 1986. - The Origins of Maya Art : Monumental Stone Sculpture of Kaminaljuyu, Guatemala, and the Southern Pacific Coast, Studies in Pre-Columbian Art and Archaeology 28, Dumbarton Oaks, Washington, D. C.

Périgny, M. de, 1911. - " Mission dans l'Amérique Centrale 1909-1910. Les ruines de Nakcun ", Nouvelles Archives des Missions Scientifiques et Littéraires, 4, pp. 1-15, n.s.

SELER, C., 1900. - Auf Alten Wegen in Mexiko und Guatemala : Reiseerinnerung und Eindrücke aus den Jahren 1895-1897, Dietrich Reimer (Ernst Vohsen), Berlin.

Sноoк, E. M. \& E. Marquis, 1996. - Secrets in Stone: Yokes, Hachas and Palmas from Southern Mesoamerica, American Philosophical Society, Philadelphia.

TAladoire, É., 1995. - « Maurice de Périgny, Archéologue ou Explorateur ? ", Journal de la Societé des Américanistes, 81, pp. 243-252.

TAUBE, K., 1992. — " The Temple of Quetzalcoatl and the Cult of Sacred War at Teotihuacan », RES 21, pp. 53-87.

Thompson, J. E. S., 1948. - An Archaeological Reconnaissance in the Cotzumalhuapa Region, Escuintla, Guatemala, Contributions to American Anthropology and History, 44, Carnegie Institution of Washington, Washington, D. C.

Vreeland, C. E. \& Bransford, J. F., 1885. — « Antiquities at Pantaleón, Guatemala », Annual Report of the Board of Regents of the Smithsonian Institution, showing the operations, expenditures, and condition of the institution for the year 1884, pp. 719-730, Smithsonian Institution, Washington, D. C.

Willey, G. R., 1966. - An Introduction to American Archaeology, volume 1 : North and Middle America, Prentice-Hall Inc., Englewood Cliff's, New Jersey.

Williams, H., 1960. — « Volcanic History of the Guatemala Highlands », University of California Publications in Geological Sciences 38, $\mathrm{n}^{\circ}$ 1, pp. 1-86, University of California Press, Berkeley. 